\title{
ИНЫЕ МЕЖБЮДЖЕТНЫЕ ТРАНСФЕРТЫ В СИСТЕМЕ БЮДЖЕТНОГО РЕГУЛИРОВАНИЯ: ТЕНДЕНЦИИ И ПЕРСПЕКТИВЫ
}

\author{
(c) 2020 Соломко Мария Николаевна \\ кандидат экономических наук, доцент кафедры финансов и кредита \\ Хабаровский государственный университет экономики и права, Россия, Хабаровск \\ E-mail: solomko_m_n@mail.ru
}

Оптимизация структуры, условий и порядка предоставления межбюджетных трансфертов является одним из направлений повышения эффективности расходов федерального и региональных бюджетов. Кроме того, распределение межбюджетных трансфертов оказывает воздействие на динамику пространственного развития, что делает успешное решение задачи по совершенствованию механизма их предоставления значимым шагом на пути к преодолению территориальных дисбалансов и экономическому росту регионов.

Актуальным вопросом теоретического и прикладного характера является совершенствование структуры межбюджетных трансфертов, т.к. разные их виды и, следовательно, механизмы перераспределения оказывают неравнозначное влияние на социально-экономическое развитие регионов (муниципальных образований) и состояние их бюджетов [2;3;5;8].

В современных научных исследованиях детально и всесторонне освещены проблемы выравнивания бюджетной обеспеченности, делегирования государственных полномочий и предоставления субвенций, долевое финансирование расходных обязательств субъектов РФ и муниципальных образований $[2 ; 4 ; 6 ; 7]$. В значительно меньшей степени раскрыты вопросы распределения иных межбюджетных трансфертов.

Этим обстоятельством предопределен выбор объекта исследования и постановка его цели. В рамках данной работы проведен анализ динамики и структуры иных межбюджетных трансфертов, предоставляемых из федерального бюджета в бюджеты субъектов РФ. Цель работы - определить роль иных межбюджетных трансфертов в структуре трансфертов и в формировании доходов региональных бюджетов и оценить перспективы их предоставления.

В течение последних двух десятилетий структура межбюджетных трансфертов из бюджетов бюджетной системы РФ, порядок и методики их распределения и предоставления претерпевали значительные изменения. Но, несмотря на реформы, в системе межбюджетных отношений сохранилось большое количество финансовых потоков, экономическое содержание которых не позволяло отнести их ни к дотациям, ни к субсидиям, ни к субвенциям. В большинстве своем такие трансферты являлись целевыми, но не предусматривали долевое финансирование и не были связаны с передачей государственных полномочий. Для их обозначения в 2007 году бюджетное законодательство был введен термин «иные межбюджетные трансферты». При этом в Бюджетном кодексе РФ в редакции от 2007 года отсутствовало их определение. В ходе внесения поправок в законодательство в 20072018 годах нормы, подробно раскрывающие суть иных трансфертов, порядок их формирования, также не были законодательно закреплены. Отчасти это объясняется тем, что иные трансферты рассматривались как «временный» инструмент бюджетного регулирования, используемый в силу невозможности оказания финансовой поддержки субъектам РФ (муниципальным образованиям) в какой-либо иной форме.

Подобное восприятие иных межбюджетных трансфертов прослеживается в целом ряде программных документов, определяющих цели и задачи бюджетной политики РФ. Например, в «Программе повышения эффективности управления общественными (государственными и муниципальными) финансами на период до 2018 года» ставится задача полного отказа от иных межбюджетных трансфертов с исключением подобной их формы из Бюджетного кодекса РФ. Несколько менее категоричный подход изложен в Основных направлениях бюджетной, налоговой, таможенно-тарифной политики РФ на период 2020-2022 годов. Этим документом предлагается проведение работы по сокращению числа иных межбюджетных трансфертов 
и ограничению оснований их предоставления случаями неполного (нечеткого) разграничения полномочий между уровнями публичной власти. Стоит отметить, что два приведенных примера не исчерпывают всех содержащихся в правовых актах указаний на необходимость уменьшения числа иных межбюджетных трансфертов и их роли в системе бюджетного регулирования. В качестве аргумента обычно выступает недостаточно прозрачный механизм их предоставления, противоречащий как общетеоретическим принципам построения финансовых отношений между уровнями власти, так и нормам законодательства [6].

В целом политика Правительства РФ в части иных межбюджетных трансфертов представляется недостаточно последовательной и формируемой в большей степени под воздействием текущей экономической ситуации, а не в рамках стратегического курса развития межбюджетных отношений. Данный тезис может быть проиллюстрирован динамикой иных межбюджетных трансфертов и их доли в структуре средств, предоставляемых из федерального бюджета в 2011-2019 гг., то есть в период, непосредственно предшествовавший разработке Программы повышения эффективности управления общественными (государственными и муниципальными) финансами, во время и сразу после её реализации (рис. 1).

За 2011-2019 годы объем межбюджетных трансфертов, предоставляемых из федерального бюджета в бюджеты субъектов РФ, увеличился более чем на 900 млрд. рублей, или 62\%. Темпы роста объемов дотаций, субсидий и субвенций составили 164\%; 109\% и 118\% соответственно. Объем иных межбюджетных трансфертов, предоставленных из федерального бюджета в 2019 году, превысил значение показателя 2011 года почти в 8,5 раза. В 2011 году их доля в структуре межбюджетных трансфертов составляла 4\%; в 2016 году - 14\%; в 2019 году - более 21 процента [9-11]. Таким образом, практика бюджетного регулирования 2011-2019 годов противоречила задачам в сфере совершенствования межбюджетных отношений.

Роль иных межбюджетных трансфертов как инструмента финансовой поддержки субъектов Федерации и решения текущих экономических и социальных задач не только не снизилась, но напротив, многократно усилилась.

Отдельные меры по сокращению числа иных межбюджетных трансфертов все же предпринимались. Например, в процессе подготовки проекта федерального бюджета на 2017 год и на плановый период 2018 и 2019 годов 19 видов иных межбюджетных трансфертов были заменены субсидиями (включая консолидированные субсидии), 9 видов - непосредственным предоставлением средств организациям из федерального бюджета. В результате в 2017 году объем иных межбюджетных трансфертов снизился на $16 \%$ по сравнению с показателем предыдущего года [10]. Стоит отметить, что согласно первоначально утвержденной редакции федерального закона о федеральном бюджете на указанный

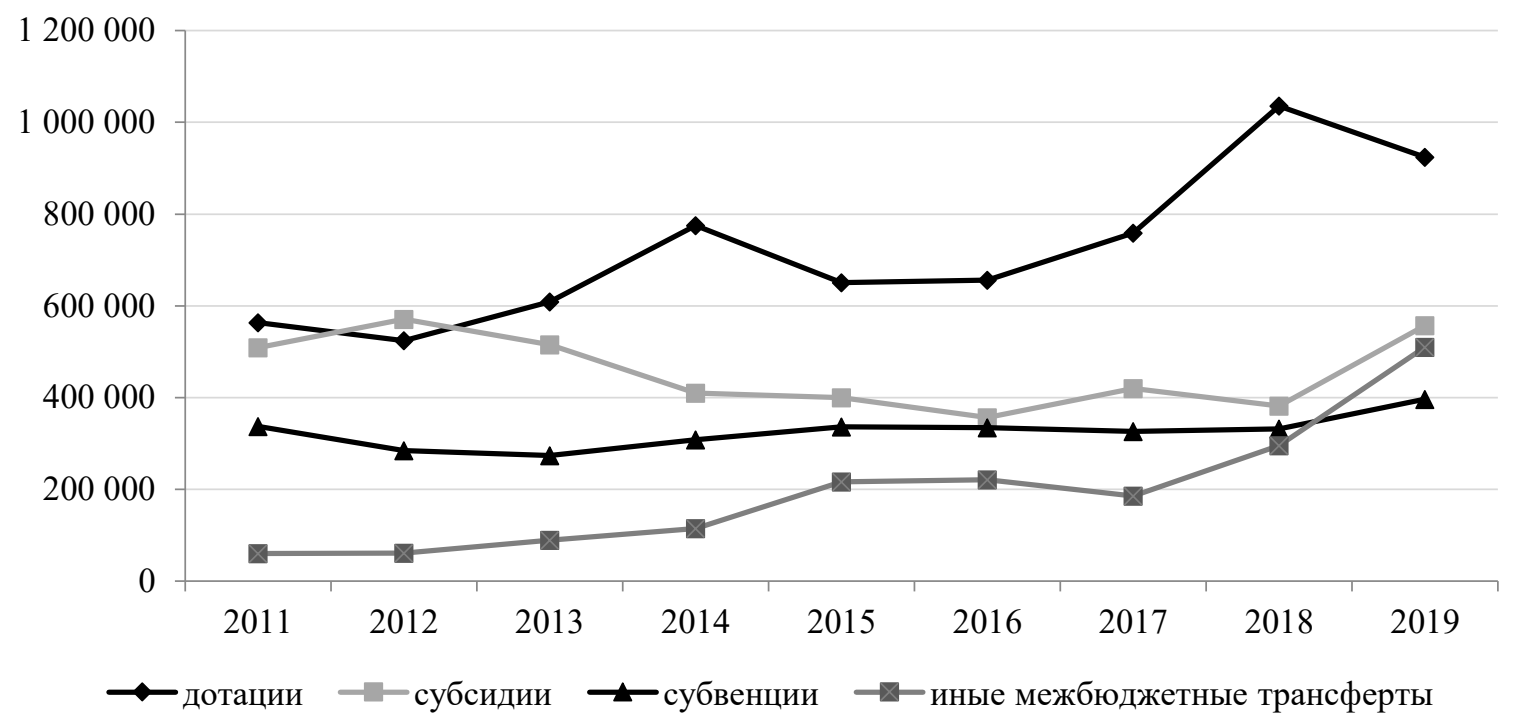

Рисунок 1. Динамика межбюджетных трансфертов из федерального бюджета в бюджеты субъектов РФ, млн. рублей 
период предусматривалось более масштабное сокращение (примерно на 30\% по сравнению с показателями 2016 года).

В 2019 году работа по переводу иных межбюджетных трансфертов в другие формы бюджетных ассигнований была активизирована. В частности, при формировании проекта бюджета на 2020 год и на плановый период 2021 и 2022 годов в форму субсидий были переведены трансферты на осуществление региональной социальной доплаты к пенсии, на создание системы ухода за лицами пожилого возраста и инвалидами, мероприятия в сфере содействия занятости и пр. Кроме того, была осуществлена замена отдельных видов иных межбюджетных трансфертов дотациями [11].

В соответствии с действующим законодательством, в основу составления расходной части федерального бюджета положен принцип скользящего трехлетнего планирования, призванный обеспечить преемственность параметров бюджетов следующих друг за другом бюджетных циклов. Безусловно, данный подход допускает корректировку показателей при переходе к следующему бюджетному циклу, но представляется, что эти изменения должны носит скорее эволюционный, а не радикальный характер. В действительности, можно наблюдать существенные расхождения по целому ряду показателей, в том числе расходам на предоставление иных межбюджетных трансфертов.

Практически на протяжении всего анализируемого периода при составлении проекта бюджета предусматривалось сокращение объема иных межбюджетных трансфертов в плановом периоде относительно отчетного, текущего и (или) очередного финансового года. Например, в федеральном законе о федеральном бюджете на 2017 год и на плановый период 2018 и 2019 годов предусматривалось, что в 2018 году иные межбюджетные трансферты составят 129 млрд. рублей. Согласно первоначально утвержденной редакции федерального закона о федеральном бюджете на 2018 год и на плановый период 2019 и 2020 годов объем иных межбюджетных трансфертов на 2018 год был запланирован в сумме 138,5 млрд. рублей. В соответствии с его уточненной редакцией объем иных межбюджетных трансфертов составлял 217,4 млрд. рублей. Для сравнения: значение данного показателя согласно уточненной сводной бюджетной росписи - 313,9 мдрд рублей (то есть на 44\% выше показателя, утвержденного в уточненной редакции закона о бюджете). Фактически иные межбюджетные трансферты были предоставлены в объеме 295,8 млрд. рублей, что на $6 \%$ меньше суммы, предусмотренной уточненной сводной бюджетной росписью и на $36 \%$ больше показателя, утвержденного в законе [10].

Стоит отметить, что по другим формам межбюджетных трансфертов также ежегодно наблюдались значительные отклонения отчетных показателей от утвержденных параметров. В частности, такая ситуация характерна для межбюджетных субсидий.

Безусловно, выявленные отклонения обусловлены различными причинами и не во всех случаях связаны с низкой эффективностью политики в сфере межбюджетных отношений.

Следующий заслуживающий внимания вопрос касается роли иных межбюджетных трансфертов в решении задач социальноэкономического развития регионов. Для ответа на него необходимо проанализировать структуру иных межбюджетных трансфертов.

В 2011 году около 70\% иных межбюджетных трансфертов приходилось на трансферты на реализацию региональных программ модернизации здравоохранения, более $5 \%$ - на лекарственное обеспечение отдельных категорий граждан.

В 2015-2016 гг. в структуре иных межбюджетных трансфертов значительную долю занимали трансферты на финансовое обеспечение дорожной деятельности и развитие транспортной инфраструктуры, вторым значимым направлением являлось выделение средств на лекарственное обеспечение отдельных категорий населения, закупку антивирусных препаратов для лиц, страдающих определенными заболеваниями. Кроме того, в этот период в федеральном бюджете предусматривались трансферты бюджетам субъектов РФ, пострадавшим в результате чрезвычайных ситуаций, а также средства на временное социально-бытовое устройство лиц, вынужденно покинувших территорию Украины. В 2016 году появляется новое направление предоставления иных межбюджетных трансфертов - финансовая поддержка хозяйствующих субъектов, зарегистрированных и осуществляющих деятельность в Калининградской области. В 2016 году их доля составила около 12\% общего объёма иных межбюджетных трансфертов, в 2018 году - увеличилась почти до 19\%. В 2017- 
2018 гг. сохраняется значительная доля трансфертов, предоставляемых с целью финансового обеспечения проектов в области дорожного хозяйства и транспортной инфраструктуры. В структуре иных межбюджетных трансфертов в 2018 году заметную долю составили трансферты на частичное возмещение затрат организаций АПК по уплате процентов по инвестиционным кредитам (более 8,5\%). В 2019 году отмечается рост числа иных межбюджетных трансфертов, при этом объём средств, выделяемых по многим направлениям, составляет менее сотой доли процента. Это объясняется локальным характером задач, на финансовое обеспечение которых выделяются средства. Среди крупнейших по объему направлений остаются дорожная деятельность (24\%), компенсация части затрат по кредитам для организаций АПК (6\%), экономическое стимулирование хозяйствующих субъектов, осуществляющих деятельность в Калининградской области (около 11\%). Снижение объёмов и удельного веса иных межбюджетных трансфертов, направленных на реализацию полномочий в сфере здравоохранения, обусловлено их заменой другими формами трансфертов.

Результаты анализа состава иных межбюджетных трансфертов могут быть систематизированы путем построения классификации, основанной на традиционных для изучения межбюджетных грантов критериях [4]. К ним относятся: наличие ограничений на направления использования средств (или иначе - степень самостоятельности получателя трансфертов в вопросах их расходования); назначение трансфертов; универсальность; регулярность предоставления. Кроме того, иные межбюджетные трансферты могут быть проанализированы в разрезе отраслевой направленности, что дополнит классификацию по назначению.

Исходя из ограничений на направления использования средств, иные межбюджетные трансферты классифицируются по трём группам:

- нецелевые иные межбюджетные трансферты (например, на компенсацию выпадающих доходов и дополнительных расходов, обусловленных решениями, принятыми федеральными органами власти);

- узкоцелевые (например, на выплату региональной социальной доплаты к пенсии; на возмещение части затрат по выплате процентов по инвестиционным кредитам организациями
$\mathrm{A \Pi K);}$

- блочные (на реализацию мероприятий, предусмотренных планами социального развития центров экономического роста субъектов РФ, входящих в состав Дальневосточного федерального округа).

Традиционное деление межбюджетных трансфертов на выравнивающие и стимулирующие не в полной мере отражает специфику иных межбюджетных трансфертов. В связи с этим нами предлагается следующая их классификация по назначению:

- трансферты, предоставляемые в целях компенсации финансовых последствий решений, принятых федеральными органами государственной власти;

- трансферты, обеспечивающие финансовую поддержку в решении социально и экономически значимых задач;

- трансферты, обеспечивающие финансовую поддержку в условиях ликвидации последствий чрезвычайной ситуации;

- трансферты, направленные на обеспечение опережающего развития отдельных регионов и экономическое стимулирование;

- трансферты, направленные на финансовое обеспечение мероприятий общегосударственного уровня (масштаба).

В свою очередь, в составе трансфертов компенсационного характера могут быть выделены трансферты, обеспечивающие частичное восполнение выпадающих доходов, и трансферты, предоставляемые в силу несовершенства разграничения полномочий между уровнями власти.

Дополняя данную классификацию «отраслевым» срезом, отметим, что основными направлениями, по которым предоставляются иные межбюджетные трансферты, являются поддержка национальной экономики (в том числе содействие развитию инфраструктуры; сельского хозяйства, предпринимательства) и здравоохранение (создание инфраструктуры оказания медицинской помощи, лекарственное обеспечение).

По третьему из предложенных признаков можно выделить универсальные иные межбюджетные трансферты, предоставляемые большинству субъектов РФ, соответствующим определенным критериям (условиям), и уникальные (индивидуальные) иные трансферты, предназначенные для бюджета только одного региона. 
Примерами таких трансфертов являются:

- иные межбюджетные трансферты на развитие транспортной инфраструктуры г. Москвы;

- трансферты бюджету Чукотского автономного округа на реализацию инвестиционных проектов по организации добычи и переработки многокомпонентных руд;

- трансферты бюджету Ульяновской области на проведение ремонтно-реставрационных работ на здании областного государственного учреждения «Ленинский мемориал» и др.

Отметим, что среди иных межбюджетных трансфертов достаточно много «уникальных».

В соответствии с четвертым критерием предлагается выделить две группы трансфертов. Первую из них составляют трансферты, предоставляемые на долгосрочной основе для решения задач постоянного характера (например, дорожная деятельность, лекарственное обеспечение граждан, выплата социальной доплаты к пенсии). Прекращение их предоставления возможно в случае замены другими формами межбюджетных трансфертов либо внесения изменений в систему разграничения полномочий между уровнями власти. Вторая группа включает трансферты непостоянного характера, предоставление которых связано с подготовкой к проведению какого-либо мероприятия, возникновением чрезвычайной (соответственно, непрогнозируемой) ситуации или необходимостью решения локальной задачи. Допустим, к этой категории можно отнести трансферты, предоставление которых осуществлялось в рамках подготовки к чемпионату мира по футболу, проходившему в России в 2018 году.

Возвращаясь к проблеме отклонений объемов фактически предоставленных трансфертов от утвержденных законом о бюджете назначений, стоит рассмотреть еще один классификационный признак иных трансфертов - плановый характер. В соответствии с ним предлагается выделять плановые трансферты, то есть те, которые предусмотрены законом о бюджете (прежде всего, его первой редакцией), и внеплановые трансферты. Отчасти предоставление внеплановых иных межбюджетных трансфертов связано с неэффективным осуществлением бюджетных полномочий главными распорядителями бюджетных средств в части распределения субсидий. В случае нарушения сроков заключения соглашения о предоставлении субсидии, соответствующему главному распорядителю бюджетных средств уменьшаются бюджетные ассигнования, предназначенные для указанных целей. Эти средства перераспределяются в пользу формирования Резервного фонда Правительства РФ и подлежат использованию на оказание финансовой поддержки субъектов РФ. Кроме того, к внеплановым трансфертам относятся средства, выделяемые из федерального бюджета в силу возникновения непредвиденных обстоятельств.

Анализ состава иных межбюджетных трансфертов позволяет сделать вывод о высоком уровне их значимости для региональных бюджетов. С их помощью осуществляется решение проблем в сфере создания дорожной и транспортной инфраструктуры, повышения инвестиционной привлекательности региона, совершенствования материально-технической базы предоставления социальных услуг, поддержки отдельных категорий населения и пр.

Роль иных межбюджетных трансфертов в формировании доходов региональных бюджетов неодинакова. В 2018 году их доля в структуре безвозмездных поступлений из бюджетов бюджетной системы составляла от $2 \%$ до $83 \%$. Минимальная доля иных межбюджетных трансфертов была характерна, главным образом, для субъектов Федерации с низким уровнем бюджетной обеспеченности (Кабардино-Балкарская Республика, Карачаево-Черкесская Республика, Республика Алтай). Наибольшую долю иные межбюджетные трансферты занимали в структуре безвозмездных поступлений в бюджеты Калининградской и Сахалинской областей (свыше 80\%). Для бюджетов большинства субъектов Федерации значение показателя составляло от 10 до $20 \%$.

В 2019 году в бюджетах 79 из 85 субъектах РФ отмечался рост объемов иных межбюджетных трансфертов, для ряда региональных бюджетов он составил два и более раз. Удельный вес иных межбюджетных трансфертов в структуре безвозмездных поступлений также увеличился в бюджетах преобладающей части регионов, что говорит о повышении их значения в финансовом обеспечении вопросов социального и экономического развития.

Опыт реформирования системы межбюджетных трансфертов показывает, что сокращение числа иных межбюджетных трансфертов, их замена другими формами регулирования возможны. Подобные изменения представляются целесообразными, если они упорядочивают и 
упрощают с организационной точки зрения механизм взаимодействия органов власти и других субъектов экономики (например, учреждений или коммерческих организаций). Являются ли иные межбюджетные трансферты востребованным и экономически обоснованным инструментом регулирования? Полагаем, что, несмотря на критику и выявленные в ходе изучения статистических и иных материалов недостатки в системе их предоставления, иные межбюджетные трансферты обладают отдельными сильными сторонами. Являясь преимущественно блочными либо узкоцелевыми трансфертами, они оставляют возможность как для согласования приоритетов федеральной и региональной политики, так и для мониторинга достижения значимых целей. Несмотря на установку на расширение финансовой самостоятельности субъектов РФ, отказ от контроля либо его ослабление едва ли уместны. Порядок предоставления многих видов иных трансфертов не предусматривает условия о долевом финансировании обязательства, что является преимуществом для реципиентов средств.

Одним из направлений совершенствования системы межбюджетных трансфертов на современном этапе остается их укрупнение (консолидация) [1; 7]. Преимущественно консолидация проводится в отношении субсидий. Полагаем, что данный механизм может получить развитие и применительно к иным межбюджетным трансфертам. Во многих зарубежных странах система трансфертов представлена блочными и нецелевыми грантами. При этом блочные гранты делятся на долевые и не предусматривающие софинансирование. Таким образом, в долгосрочной перспективе иные межбюджетные трансферты, носящие постоянный или долговременный характер, могут трансформироваться в блочные гранты, не требующие долевого финансирования со стороны реципиента.

Проведенное исследование позволило сформулировать следующие выводы.

Иные межбюджетные трансферты рассматриваются в качестве вспомогательного инструмента бюджетного регулирования, применение которого, как правило, обусловливается невозможностью предоставления средств в какой-либо иной форме. Несмотря на установку на сокращение доли иных межбюджетных трансфертов в структуре средств, предоставляемых из федерального бюджета бюджетам субъектов РФ, в среднесрочном периоде их сумма возрастала опережающими темпами, для отдельных субъектов Федерации иные межбюджетные трансферты стали основным (либо значимым) каналом поддержки из федерального бюджета. Характер задач, для решения которых выделяются иные межбюджетные трансферты, отражает их общественную значимость и делает, по крайней мере, нецелесообразным отказ от подобной формы регулирования. Проблема структуры межбюджетных трансфертов должна рассматриваться в более широком контексте нежели, чем просто определение оптимального соотношения между различными формами предоставления средств. Межбюджетные трансферты призваны ликвидировать или минимизировать дисбалансы, устранение которых невозможно в рамках разграничение обязательств, полномочий по управлению доходами и источников их формирования. Выбор форм трансфертов, соответственно, должен основываться на балансе интересов публично-правовых образований (согласование приоритетов политики и высокий уровень управляемости, с одной стороны, и самостоятельность в решении текущих, организационных вопросов распоряжения средствами, с другой). Многообразие видов иных межбюджетных трансфертов, основанное на рамочном характере их регулирования и возможности включения в их состав практически любых межбюджетных потоков, не обладающих признаками дотаций, субсидий и субвенций, позволяет определить оптимальные механизм поддержки регионального развития. При помощи иных межбюджетных трансфертов может быть реализован как территориальный, так и отраслевой подход к управлению развитием экономики. Все изложенные аргументы говорят в пользу необходимости совершенствования порядка и методик предоставления иных межбюджетных трансфертов, реализации мер по их консолидации, а не категоричного отказа от их использования, обусловленного «непрозрачностью». 


\section{Библиографический список}

1. Арлашкин И. Ю., Ганган А.С., Дерюгин А.Н., Прока К.А. Предоставление блочных трансфертов: опыт США, Австралии и Канады // Научно-исследовательский финансовый институт. Финансовый журнал. 2016. № 1 (29). С. 41-49.

2. Бухарский В. В., Лавров А.М. Оценка выравнивающего и стимулирующего эффектов межбюджетных трансфертов субъектам РФ // Научно-исследовательский финансовый институт. Финансовый журнал. 2017. № 1 (35). C. 9-21.

3. Бухвальд E. «Саморазвитие» регионов и приоритеты регулирования пространственной структуры экономики // Федерализм. 2018. № 2. С. 32-45.

4. Голованова Н.В. Межбюджетные трансферты: многообразие терминов и российская практика // Научноисследовательский финансовый институт. Финансовый журнал. 2018. №2. C. 24-35. DOI: 10.31107/20751990-2018-2-24-35

5. Левина В.В. Согласование интересов в бюджетной политике субъектов Российской Федерации // Федерализм. 2019. № 1 (93). С. 100-117.

6. Печенская М.А. Развитие межбюджетных отношений в России в 2000-2005 гг.// Проблемы прогнозирования. 2017. № 2 (161). С. 117-130.

7. Силуанов А.Г. Пути совершенствования межбюджетных отношений в Российской Федерации // Российское предпринимательство. 2012. № 2 (100). С. 43-50.

8. Тимушев Е.Н. Способы совершенствования механизмов предоставления межбюджетных трансфертов в бюджетной системе РФ // ЭКО. 2016. № 7(505). С. 139-152.

9. Пояснительная записка к проекту Федерального закона «Об исполнении федерального бюджета за 2018 год».

10. Заключение Счётной палаты РФ на проект Федерального закона «О федеральном бюджете на 2017 год и на плановый период 2018 и 2019 годов».

11. Заключение Счётной палаты РФ на проект Федерального закона «О федеральном бюджете на 2020 год и на плановый период 2021 и 2022 годов» 